\title{
High Incidence of Preoperative Mild Cognitive Impairment in Elderly Surgical Patients
}

Daniel Newman MSc, Beth-Ann Cummings MD MSc, Howard Chertkow MD, Shannon Fraser MD MSc, Simon Bergman MD MSc

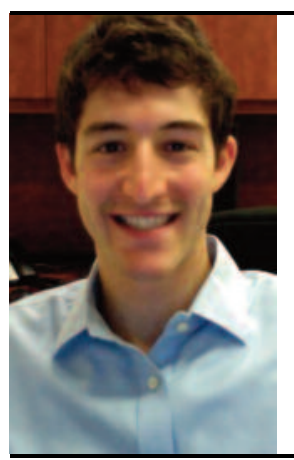

\section{About the Authors}

Daniel Newman (left) is a 2nd-year medical student at Queen's University, in Kingston, Ontario, and a former research assistant in the Department of Surgery at Lady Davis Institute for Medical Research, Jewish General Hospital, in Montreal, Quebec. Beth-Ann Cummings is a member of the Department of Medicine, Centre for Medical Education, McGill University, in Montreal. Howard Chertkow is a member of the Department of Clinical Neurosciences at McGill University; and the Lady Davis Institute for Medical Research, Jewish General Hospital. Shannon Fraser is a member of the Department of Surgery at McGill University. Simon Bergman is a member of the Department of Surgery, McGill University; and the Lady Davis Institute for Medical Research, Jewish General Hospital. Correspondence may be directed to beth.cummings@mcgill.ca.

\section{Summary}

Post-operative delirium in elderly patients is associated with higher mortality and longer lengths of stay. This prospective observational study investigated the incidences of preoperative mild cognitive impairment (MCI) and post-operative delirium among elderly patients undergoing elective surgery at the authors' institution, the relationship between MCI and delirium, and the impact of delirium on surgical morbidity and lengths of stay. The authors found that although MCI did not predict post-operative delirium, the high incidence of MCI in elective surgery patients warrants further study.

\section{Résumé}

Le délire postopératoire chez la personne âgée est un facteur pronostique de mortalité accrue et de prolongation du séjour hospitalier. L'étude observationnelle prospective présentée ici examine l'incidence du trouble cognitif mineur préopératoire et du délire postopératoire chez des personnes âgées subissant une intervention chirurgicale non urgente à l'établissement des auteurs, la relation entre le trouble cognitif mineur préopératoire et le délire, et les répercussions du délire des points de vue de la morbidité chirurgicale et de la durée de l'hospitalisation. Les auteurs constatent que même si la présence préopératoire d'un trouble cognitif mineur ne laisse présager en rien un délire postopératoire, il y a lieu de creuser la question de l'incidence élevée de trouble cognitif mineur chez les patients subissant une intervention chirurgicale non urgente.

\section{Background}

Delirium is an acute confusional state characterized by impaired cognitive function, fluctuating levels of consciousness, reduced attention, and perceptual disturbances. ${ }^{1,2}$ It occurs in up to $40 \%$ of patients following non-cardiac surgery. ${ }^{3-6}$ Delirium is associated with increased post-operative morbidity and mortality, poor functional recovery, and longer lengths of hospital stay. ${ }^{3,5}$
Mild cognitive impairment (MCI) is defined as cognitive decline greater than that predicted by age. MCI does not interfere with day-to-day activities ${ }^{7}$ and has a prevalence of $3-19 \%$ in the non-hospitalized elderly population. MCI is clinically important because it represents a borderline state between the normal cognitive decline of aging and the development of dementia. ${ }^{8}$

A correlation between preoperative cognitive decline and post-operative delirium, in non-cardiac surgery, has been 
suggested by several authors. ${ }^{3-6}$ Studies have used different cutoff scores for the Mini-Mental State Examination (MMSE), or changes in the MMSE score, to predict delirium. Regarding the MCI, only a few studies have evaluated this condition using a validated measurement tool. ${ }^{9}$

The Montreal Cognitive Assessment (MoCA) is a quick cognitive screening tool with high sensitivity and specificity for detecting MCI. It is also superior to the MMSE for detecting MCI. ${ }^{10,11}$ To our knowledge, it has not been used to investigate the relationship between MCI and delirium in an elderly surgical population. Patients aged at least 65 years now constitute $60 \%$ of the workload in general surgery, and this number is growing. ${ }^{12}$ Therefore, it is important for perioperative care practitioners to understand the impact of MCI.

We hypothesized that the presence of preoperative MCI is predictive of the development of post-operative delirium. The primary objective of this study was to determine the prevalence of preoperative MCI in elderly surgical patients at a single academic tertiary care hospital. Secondary objectives were to describe the association between MCI and post-operative delirium, and measure the impact of post-operative delirium on post-operative complications and length of stay (LOS).

\section{Methods}

This prospective observational study enrolled patients aged $\geq 70$ years undergoing elective general surgery, vascular surgery, or head and neck surgery who presented to our institution's presurgical screening centre between May 1, 2010, to August 30, 2010. Exclusion criteria were the following:

- The surgery type was not general, vascular, or head and neck (as determined by medical record)

- Emergent admission

- The patient was not fluent in French or English (as determined by patient interview)

- The patient had known active and untreated psychiatric disease (as determined by patient interview)

- The patient had known dementia (as determined by patient interview)

- The patient had an unadjusted MMSE score <23 (as determined by patient interview)

- The patient had preoperative delirium (as determined by patient interview)

- There was an inability to complete any of the preoperative cognitive assessments (as determined by patient interview)

- The predicted post-operative LOS was $<2$ days (in order to select for major surgical procedures and provide sufficient opportunity to detect in-hospital delirium; as determined by medical record)

This study was approved by the institutional ethics review board of McGill University.

A preoperative baseline assessment was conducted by the investigators. These assessments were all performed in the morning, and in a quiet area of the pre-surgical screening centre. Demographic data were collected: age, gender, Charlson Comorbidity Index (CCI), education level, diagnosis, and procedure type. The following cognitive assessments were performed:

- MMSE: A validated screening tool for dementia that has limited sensitivity in patients with MCI. . $^{11,13,14}$

- MoCA: A brief cognitive examination that detects MCI with 90\% sensitivity. Adjusted MoCA scores were calculated by adding a point if the study participant had $<12$ years of education. ${ }^{10}$ Patients with a score $<26$ were considered to have MCI. ${ }^{10}$

- Confusion Assessment Method (CAM): Criteria used to screen for delirium. Patients were considered to have delirium if they tested positive on the CAM, according to standard, published criteria (acute onset and fluctuating course, inattention, disorganized thinking, altered level of consciousness). ${ }^{15}$

Bedside postoperative assessments were performed daily as of post-operative day 1, for 7 days or until discharge. All preoperative and post-operative cognitive assessments were performed by the same investigator, who was experienced with administering these tools, as per Inouye et al. ${ }^{15} \mathrm{~A}$ practising clinician independently confirmed all diagnoses of delirium. If there was disagreement, the clinician's diagnosis was recorded. Data regarding LOS and post-operative complications, as defined by the National Surgical Quality Improvement Program (NSQIP) ${ }_{1}^{16}$ were abstracted from the medical record.

A descriptive analysis of demographic and preoperative cognitive data was performed; this was then stratified by the presence or absence of delirium. To determine the association between MCI and delirium, multivariable logistic regression analysis was performed with delirium (yes/no) as the dependent variable. Odds ratios and $95 \%$ confidence interval $(\alpha=0.05, \beta$ $=0.80$ ) were calculated for the following independent variables: age, gender, CCI, and MCI. The number of patients with at least one complication and their LOS were compared for those with and without delirium, using the Pearson's chi-square and Student $t$ tests, respectively. Significance was defined as $p<.05$. PASW Statistics 18 software (Somers, New York) was used for analysis. 


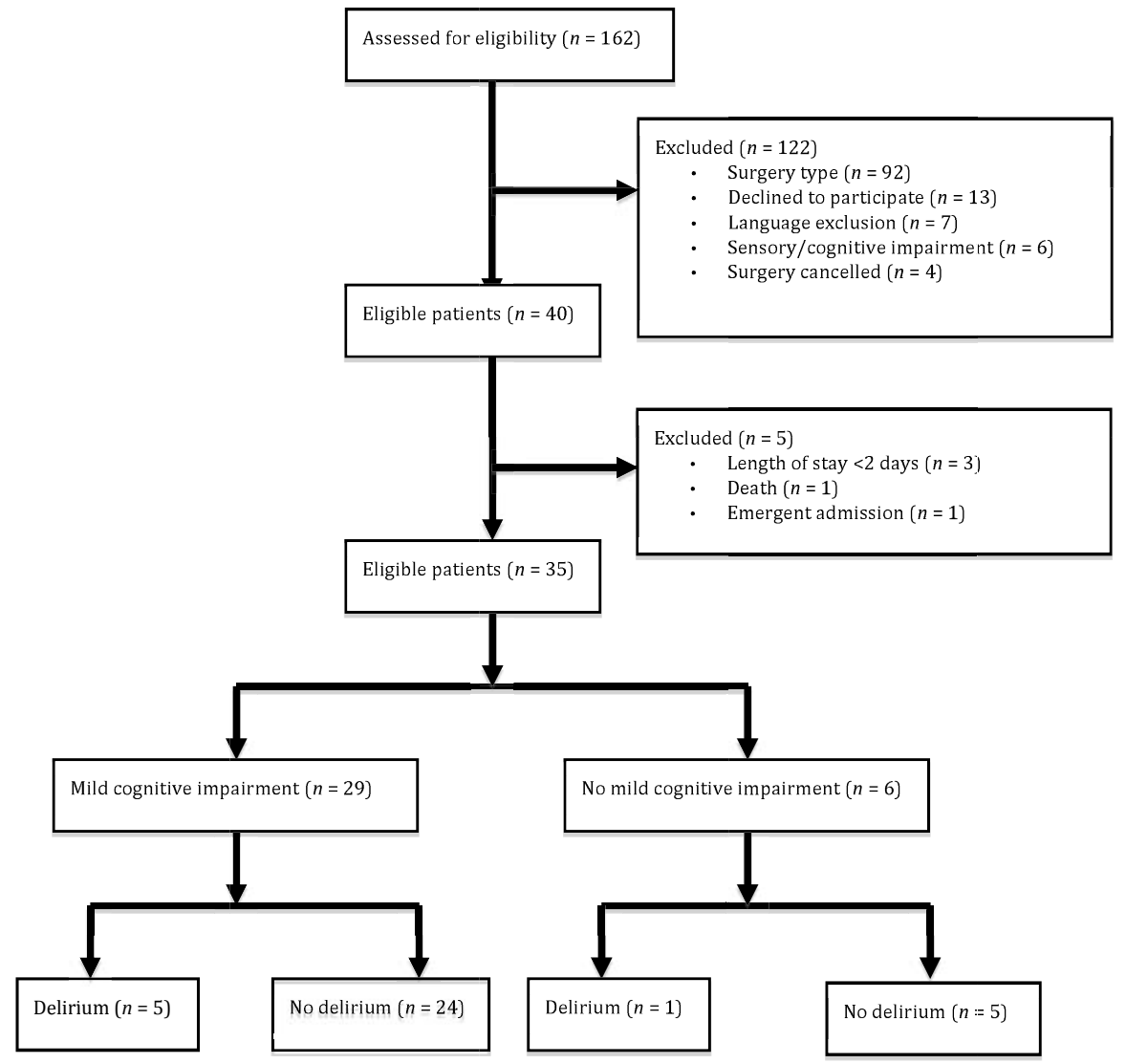

Figure 1. Patient recruitment flowchart.

Table 1. Baseline Patient Characteristics Stratified by the Presence or Absence of Post-operative Delirium

\begin{tabular}{lccc} 
& Total $^{*}, \boldsymbol{n}=\mathbf{3 5}(\%)$ & Delirium $^{*}, \boldsymbol{n}=\mathbf{6}(\%)$ & No Delirium ${ }^{*}, \boldsymbol{n}=\mathbf{2 9}(\%)$ \\
\hline Age (y) & $78.3 \pm 5.6$ & $81 \pm 5.8$ & $77.8 \pm 5.5$ \\
\hline Gender & & & \\
- Male & $17(49)$ & $1(16.7)$ & $16(55.2)$ \\
- Female & $18(51)$ & $5(83.3)$ & $13(44.8)$ \\
\hline CCl & $2.3 \pm 1.9$ & $3.7 \pm 2.9$ & $2.0 \pm 1.5$ \\
\hline
\end{tabular}

\section{Procedure type}

- General surgery
- Vascular surgery

$22(62.9)$

$11(31.4)$

- ENT surgery

Cancer diagnosis

Education level

- None

- Elementary

- High school

- University

- Postgraduate

MoCA score

MCl present

MMSE score

$2(5.7)$

$23(65.7)$

\section{$1(2.8)$}

$14(40)$

12 (34.3)

$7(20)$

$1(2.8)$

$21.8 \pm 3.7$

$29(85.3)$

$27.5 \pm 1.7$

2 (33.3)

2 (33.3)

$2(33.3)$

$4(66.7)$

$$
0(0)
$$

$4(66.7)$

$1(16.7)$

$1(16.7)$

$0(0)$

$20.8 \pm 4.4$

$5(83.3)$

$27.5 \pm 2.4$

$20(69.0)$

$9(31.0)$

$0(0)$

$19(65.5)$

$\mathrm{CCl}=$ Charlson Comorbidity Index; ENT = ear, nose and throat; MoCA = Montreal Cognitive Assessment; $\mathrm{MCl}=$ mild cognitive impairment; MMSE = Mini-Mental State Examination.

*Data are presented as absolute number $(\%)$ or mean \pm standard deviation.

\section{Results}

From May 1, 2010, to August 30, 2010, 162 consecutive patients met inclusion criteria. One hundred twenty-two patients were excluded before baseline assessment, most often due to surgery type; five were excluded after initial assessments were performed, but prior to surgery (Figure 1). There was no withdrawal, loss to follow-up, or missing data for the 35 patients included in the final analysis. The mean age of study participants was $78.3 \pm 5.6$ years. Demographic data are summarized in Table 1. The indication for surgery was cancer in 23 patients $(65.7 \%)$ and vascular disease in the remaining $12(34.3 \%)$. The mean preoperative MoCA score was 21.8 \pm 3.7 . Twentynine patients scored below normal on the MoCA, corresponding to an $82.8 \%$ incidence of MCI. The mean preoperative MMSE score was 27.5 \pm 1.7 . All patients with a MCI, and all patients who developed delirium, scored in the normal range on the MMSE.

Post-operative delirium occurred in six patients (17.1\%). Patients who developed delirium had an initial MoCA score of $20.8 \pm 4.4$, whereas those who did not had an initial MoCA of $22.1 \pm 3.6$. There was a trend toward patients with delirium being older, female, less educated, suffering from a greater burden of comorbid disease, and undergoing vascular or head and neck procedures. However, MCI, patient characteristics, and surgical factors were not significantly associated with the development of post-operative delirium when included in the regression model (Table 2).

Five analyzed patients (14.2\%) developed at least one post-operative complication: stroke, unplanned reintubation, a urinary tract infection, 
Table 2. Logistic Regression with Delirium as the Dependent Variable

\begin{tabular}{lll} 
Variable & OR & $95 \% \mathrm{Cl}$ \\
\hline Age & 1.08 & $0.89-1.31$ \\
\hline Gender & 0.12 & $0.01-1.49$ \\
\hline $\mathrm{CCl}$ & 1.69 & $0.92-3.12$ \\
\hline $\mathrm{MCl}$ & 0.19 & $0.01-3.87$
\end{tabular}

$\mathrm{CCl}=$ Charlson Comorbidity Index; $\mathrm{Cl}=$ confidence interval; $\mathrm{MCl}=$ mild cognitive impairment; $\mathrm{OR}=$ odds ratio.

or death (two patients, both beyond 1 week). Mean LOS was 12.7 \pm 10.8 days (range $4-54$ days). Those who developed delirium and those who did not were at equivalent risk for developing at least one post-operative complication $(p=.7)$. However, patients who developed delirium had a significantly longer LOS (22.7 \pm 17.4 versus $10.7 \pm 7.9$ days, $p=.01)$.

\section{Discussion}

Despite the limitation of small numbers, our incidence of $83 \%$ of MCI in elective surgical patients 70 years and older is much higher than the $1.7-22.6 \%$ prevalence reported in the general elderly population. ${ }^{8}$ The high incidence of MCI may reflect a non-representative sample or technical issues, such as our clinic environment and investigator experience. However, the MoCA is objective, easy to administer, and demonstrates excellent interrater and test-retest reliability. ${ }^{10}$ Alternatively, we may have accurately estimated the incidence of MCI by using a more sensitive measure of cognitive ability (i.e., the MoCA rather than the MMSE).

Our patients all underwent surgery either for vascular disease or cancer. Vasculopathy may play a role in the pathophysiology of MCI, ${ }^{17}$ thereby increasing $\mathrm{MCI}$ rates in those with cardiovascular risk factors, ${ }^{18}$ as well as heart failure. ${ }^{19}$ This has been reported in non-surgical populations, where $17-80 \%$ of patients with symptomatic dilated cardiomyopathy had varying degrees of cognitive impairment. ${ }^{20}$ Pereira et al. found cognitive dysfunction in up to $55 \%$ of patients with advanced cancer, while others have reported rates as high as $90 \% .{ }^{21}$

Publications from various jurisdictions have suggested different cut-off points. For instance, Rossetti et al. reported on MoCA scores from Texas. ${ }^{22}$ Compared with our Montreal study, the Caucasian group of normal controls in their study was considerably younger (52.9 versus 72.8 years) and had slightly lower mean MoCA scores (25.6 versus 26.9). In the other ethnic groups, they found substantial associations between age and education and MoCA score. Subjects in the original Montreal study were excluded if they had subjective complaints of memory loss, systemic illness, drug or alcohol use, or any abnormality on in-depth neuropsychological assessment, neurological examination, and brain imaging studies. ${ }^{10}$ Had the same strict criteria been applied to the community subjects in Rossetti et al.'s study, their results may have been similar to the Montreal cutoff scores. ${ }^{23}$ Taken together, our two studies suggest that vascular disease is associated with a much higher rate of subtle cognitive impairment than was previously recognized. Given that approximately half of elderly individuals have some brain pathology at death, ${ }^{24}$ we would hesitate to apply norms derived from a community sample rather than subjects with stricter criteria of admission to a normative comparison group: doing so would underestimate the rate of MCI associated with vascular or degenerative disease.

Seventeen percent of our patients developed post-operative delirium, which is comparable to previous studies showing an incidence of post-operative delirium of $15-40 \% \cdot{ }^{3-6}$ In our study, patients who developed delirium seemed to be slightly older, were more often female, had higher mean CCI scores, had more vascular procedures, and were on average less educated. However, this did not reach significance in our model. Others have shown that these are important risk factors for post-operative delirium. - $^{3-}$ ${ }^{6}$ On average, patients who developed post-operative delirium had lower MoCA scores; however, MCI was not significantly associated with the development of post-operative delirium. Nevertheless, among patients who developed post-operative delirium, only one did not have MCI.

This study has important limitations, most notably the small sample size. Also, the interviewer was not blinded to patients' preoperative cognitive scores. Although the CAM criteria allow objective identification of delirium, previous knowledge of cognitive scores could have biased the diagnosis. In addition, this study did not control for known delirium risk factors, including intraoperative hemorrhage, operative time, preoperative functional status, prior delirium or alcohol abuse, or the use of narcotics or benzodiazepines. In addition, functional impairment was not measured; however, that would have detected dementia rather than $\mathrm{MCI}$ (where no functional impairment is measured).

Given the high incidence (83\%) of MCI among elderly surgical patients undergoing surgery for cancer or vascular disease, investigations should further examine the incidence of $\mathrm{MCI}$ in our entire elderly surgical patient population, and better determine its impact on recovery and future cognitive status. Our work also argues for wider preoperative MCI screening, along with screening for dementia and preoperative delirium, alongside preoperative optimization of modifiable factors. ${ }^{25}$ Finally, while patients with MCI should be competent to make medical decisions, it is prudent to involve their caregivers in preoperative discussions. 


\section{CSIM Mission Statement}

\section{Mission Statement}

The CSIM is a non-profit professional society that promotes the health and well being of Canadian patients, their communities, and their health care systems. We seek to foster leadership and excellence in the practice of General Internal Medicine (GIM) through research, education, and advocacy for health promotion and disease management.

\section{Acknowledgements}

This study was presented at the Canadian Association of General Surgeons Annual Meeting in September 2011.

\section{References}

1. Robinson TN, Eiseman B. Postoperative delirium in the elderly: diagnosis and management. Clin Interv Aging 2008;3:351-5.

2. Inouye SK. Delirium in hospitalized elderly patients: recognition, evaluation, and management. Conn Med 1993;57:309-15.

3. Weed HG, Lutman CV, Young DC, et al. Preoperative identification of patients at risk for delirium after major head and neck cancer surgery. Laryngoscope 1995;105:1066-8.

4. Sasajima Y, Sasajima T, Uchida H, et al. Postoperative delirium in patients with chronic lower limb ischaemia: what are the specific markers? Eur $j$ Vasc Endovasc Surg 2000;20:132-7.

5. Minden SL, Carbone LA, Barsky A, et al. Predictors and outcomes of delirium. Gen Hosp Psychiatry 2005;27:209-14.

6. Rudolph JL, Jones RN, Rasmussen LS, et al. Independent vascular and cognitive risk factors for postoperative delirium. Am J Med 2007;120:807-13.

7. Gauthier S, Reisberg B, Zaudig M, et al. Mild cognitive impairment. Lancet 367:1262-70.

8. Ritchie K. Mild cognitive impairment: an epidemiological perspective. Dialogues Clin Neurosci 2004;6:401-8.

9. Noimark D. Predicting the onset of delirium in the post-operative patient. Age Ageing 2009;38:368-73.

10. Nasreddine ZS, Phillips NA, Bedirian V, et al. The Montreal Cognitive Assessment, MoCA: a brief screening tool for mild cognitive impairment. J Am Geriatr Soc 2005;53:695-9.

11. Zadikoff C, Fox SH, Tang-Wai DF, et al. A comparison of the Mini Mental State Exam to the Montreal Cognitive Assessment in identifying cognitive deficits in Parkinson's disease. Mov Disord 2008;23:297-9.

12. Etzioni DA, Liu JH, et al. The aging population and its impact on the surgery workforce. Hagerstown (MD): Lippincott Williams \& Wilkins; 2003.

13. Folstein MF, Folstein SE, McHugh PR. "Mini-mental state": a practical method for grading the cognitive state of patients for the clinician. J Psychiatr Res 1975;12:189-98.

14. Wind AW, Schellevis FG, Van Staveren G, et al. Limitations of the MiniMental State Examination in diagnosing dementia in general practice. Int J Geriatr Psychiatry 1997;12:101-8.

15. Inouye SK, van Dyck CH, Alessi CA, et al. Clarifying confusion: the confusion assessment method. Ann Intern Med 1990;113:941-8.

16. Khuri SF. The NSQIP: a new frontier in surgery. Surgery 2005;138:837-43

17. Beeri MS, Ravona-Springer R, Silverman JM, et al. The effects of cardiovascular risk factors on cognitive compromise. Dialogues Clin Neurosci 2009;11:201-12.

18. Tervo S, Kivipelto M, Hanninen T, et al. Incidence and risk factors for mild cognitive impairment: a population-based three-year follow-up study of cognitively healthy elderly subjects. Dement Geriatr Cogn Disord 2004;17:196-203.

19. Vogels RLC, Scheltens P, Schroeder-Tanka JM, et al. Cognitive impairment in heart failure: a systematic review of the literature. Eur J Heart Fail 2007;9:440-9.

20. Schall RR, Petrucci RJ, Brozena CS, et al. Cognitive function in patients with symptomatic dilated cardiomyopathy before and after cardiac transplantation. J Am Coll Cardiol 1989;14(7):1666-72.

21. Pereira J, Hanson J, Bruera E. The frequency and clinical course of cognitive impairment in patients with terminal cancer. Cancer 1997;79:835-42.

22. Rossetti HC, Lacritz LH, Cullum CM, et al. Normative data for the Montreal Cognitive Assessment (MoCA) in a population-based sample. Neurology 2011;77:1271-5.

23. Nasreddine ZS, Phillips N, Chertkow H. Normative data for the Montreal Cognitive Assessment (MoCA) in a population-based sample [author reply]. Neurology 2012;78:765-6.

24. Schneider JA, Aggarwal NT, Barnes L, et al. Neuropathology of older persons with and without dementia from community versus clinic cohorts. J Alzheimers Dis 2009;18:691-701.

25. Assessing care of vulnerable elders-3 quality indicators. J Am Geriatr Soc 2007;55 Suppl 2:S464-87.

\section{Vision}

We believe that General Internal Medicine in Canada plays a central role in the training of current and future clinicians, in clinical research, in patient care, in health promotion, and in health advocacy; and that it unites a body of knowledge, values, and principles of care that lay the foundation for excellence in the Canadian health care system.

\section{Values}

We embrace the ethical and professional standards that are common to all healing professions, as well as the specific values of generalism, teamwork, competency-based training, life-long learning, evidence-based medicine, holism, and humane, patient-centered care.

\section{Mission}

La Société canadienne de médecine interne (SCMI) est une association professionnelle sans but lucratif qui entend promouvoir la santé et le bienêtre des patients, des collectivités et des systèmes de santé canadiens. Elle souhaite également promouvoir le leadership et l'excellence dans l'exercice de la médecine interne générale en favorisant la recherche, l'éducation, la promotion de la santé et la gestion des soins thérapeutiques.

\section{Vision}

La Société a l'intime conviction que la médecine interne générale occupe une place centrale dans la formation des cliniciens aujourd'hui et à l'avenir, dans la recherche clinique, dans la prestation des soins et des services de santé et dans la promotion de la santé, et que la discipline se fonde sur un savoir, des valeurs et des principes thérapeutiques essentiels à la poursuite de l'excellence dans le système de santé canadien.

\section{Valeurs}

La Société fait sienne les normes éthiques et professionnelles communes aux professions de la santé ainsi que les valeurs particulières du généralisme, du travail d'équipe, de la formation axée sur les compétences, de l'éducation permanente, de la médecine factuelle, de l'holisme et des soins et des services de santé humains, centrés sur le patient.

\section{CSIM Continuing Professional Development Mission Statement}

Our ultimate goal is to go beyond the simple transmission of information. Our goal is to make a lasting impact on the knowledge, skills and attitudes of clinicians and future clinicians; to narrow the theory to practice gap; to improve the health of our patients and of all Canadians.

\section{Mission de la SCMI sur le plan du développement professionnel continu}

Notre but ultime déborde du cadre de la simple transmission d'information. Il consiste à produire un effet durable sur le savoir, les compétences et les attitudes du médecin, à combler l'écart qui sépare la théorie de la pratique, à améliorer la santé de nos patients et de tous les Canadiens. 